\title{
Characterization and Production of Rhamnolipid Biosurfactant in Recombinant Escherichia coli Using Autoinduction Medium and Palm Oil Mill Effluent
}

\section{Sony Suhandono ${ }^{1 *}$}

https://orcid.org/0000-0002-2248-3520

\author{
Subhan Hadi Kusuma ${ }^{1}$ \\ https://orcid.org/0000-0002-5530-3901
}

\author{
Karlia Meitha ${ }^{2}$ \\ https://orcid.org/0000-0002-8392-6807
}

\begin{abstract}
${ }^{1}$ Nanoscience and Nanotechnology Research Centre, Institut Teknologi Bandung, Bandung, West Java, Indonesia;
\end{abstract} ${ }^{2}$ School of Life Science and Technology, Institut Teknologi Bandung, Bandung, West Java, Indonesia.

Editor-in-Chief: Paulo Vitor Farago

Associate Editor: Luiz Gustavo Lacerda

Received: 2020.05.15; Accepted: 2020.12.18.

*Correspondence: sony@sith.itb.ac.id; Tel.: +62 821-1511-9917 (S.S.).

\section{HIGHLIGHTS}

- Recombinant E. coli can produce mono-rhamnolipid and di-rhamnolipid biosurfactants.

- Rhamnolipid congeners were identified using HRMS.

- Di-rhamnolipid has lower surface tension and CMC than mono-rhamnolipid.

- Rhamnolipid production have been optimized to enhance rhamnolipid yield.

Abstract: Rhamnolipid is a potent biodegradable surfactant, which frequently used in pharmaceutical and environmental industries, such as enhanced oil recovery and bioremediation. This study aims to engineer Escherichia coli for the heterologous host production of rhamnolipid, to characterize the rhamnolipid product, and to optimize the production using autoinduction medium and POME (palm oil mill effluent). The construction of genes involved in rhamnolipid biosynthesis was designed in two plasmids, pPM RHLAB (mono-rhamnolipid production plasmid) and pPM RHLABC (di-rhamnolipid production plasmid). The characterization of rhamnolipid congeners and activity using high-resolution mass spectrometry (HRMS) and critical micelle concentration (CMC). In order to estimate rhamnolipid yield, an oil spreading test was performed. HRMS and CMC result show E. coli pPM RHLAB mainly produced mono-rhamnolipid (Rha- $\left.\mathrm{C}_{14: 2}\right)$ with $900 \mathrm{mg} / \mathrm{L}$ and $35.4 \mathrm{mN} / \mathrm{m}$ of $\mathrm{CMC}$ and surface tension value, whereas $E$. coli pPM RHLABC mainly produced di-rhamnolipid (Rha-Rha- $\mathrm{C}_{10}$ ) with $300 \mathrm{mg} / \mathrm{L}$ and $34.3 \mathrm{mN} / \mathrm{m}$ of CMC and surface tension value, respectively. The optimum condition to produce rhamnolipid was at $20 \mathrm{~h}$ cultivation time, $37^{\circ} \mathrm{C}$, and $\mathrm{pH} 7$. In this condition, the maximum rhamnolipid yield of $1245.68 \mathrm{mg} / \mathrm{L}$ using autoinduction medium and $318.42 \mathrm{mg} / \mathrm{L}$ using $20 \%(\mathrm{v} / \mathrm{v})$ of POME. In conclusion, the characteristics of the rhamnolipid by recombinant $E$. coli is very promising to be used in industries as the most economical way of producing rhamnolipid. 
Keywords: rhamnolipid; Escherichia coli; biosurfactant; autoinduction medium; POME.

\section{INTRODUCTION}

Rhamnolipid is a glycolipid biosurfactant that is naturally produced by Pseudomonas aeruginosa [1]. Many rhamnolipid congeners have been identified as having one or two rhamnose residues and $\beta$-hydroxy fatty acid chain $\left(\mathrm{C}_{8}-\mathrm{C}_{16}\right)$ to form mono-rhamnolipid and di-rhamnolipid congeners [2]. As a biosurfactant, rhamnolipid has highest potential prospects, such as biodegradability and non-toxicity compared to synthetic surfactants, low levels of critical micelle concentration (CMC), high emulsion capacity and good solubility that could potentially be used in the pharmaceutical, agricultural industries, and enhanced oil recovery technology [3].

Rhamnolipid biosynthesis is linked to three genes, $r h / A$, $r h / B$, and $r h / C$. $r h / A$ encodes the RhIA enzyme that catalyzes the synthesis of the fatty acid dimer of rhamnolipids and free (3-(3-hydroxyalkanoxyloxy) alkanoic acids (HAA). rhIB encodes rhamnosyltransferases I (RhIB), which catalyzes the transfer of activated L-rhamnose to HAA and generates mono-rhamnolipid. rh/C encodes rhamnosyltransferases II (RhIC), which catalyzes the transfer of activated L-rhamnose to mono-rhamnolipid and generates di-rhamnolipid (Figure 1) $[4,5]$. Rhamnolipid synthesized by $P$. aeruginosa are the most frequently studied of biosurfactant. However, $P$. aeruginosa is an opportunistic pathogenic bacterium, therefore limited to industrial-scale production [6]. The pathogenicity of $P$. aeruginosa for rhamnolipid production can be overcome through genetic engineering in heterologous hosts, such as Escherichia coli.

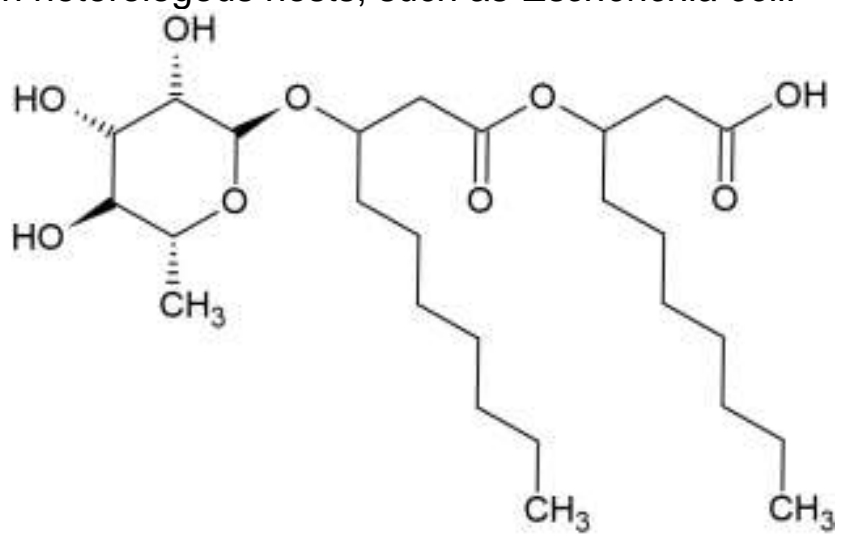

(a)

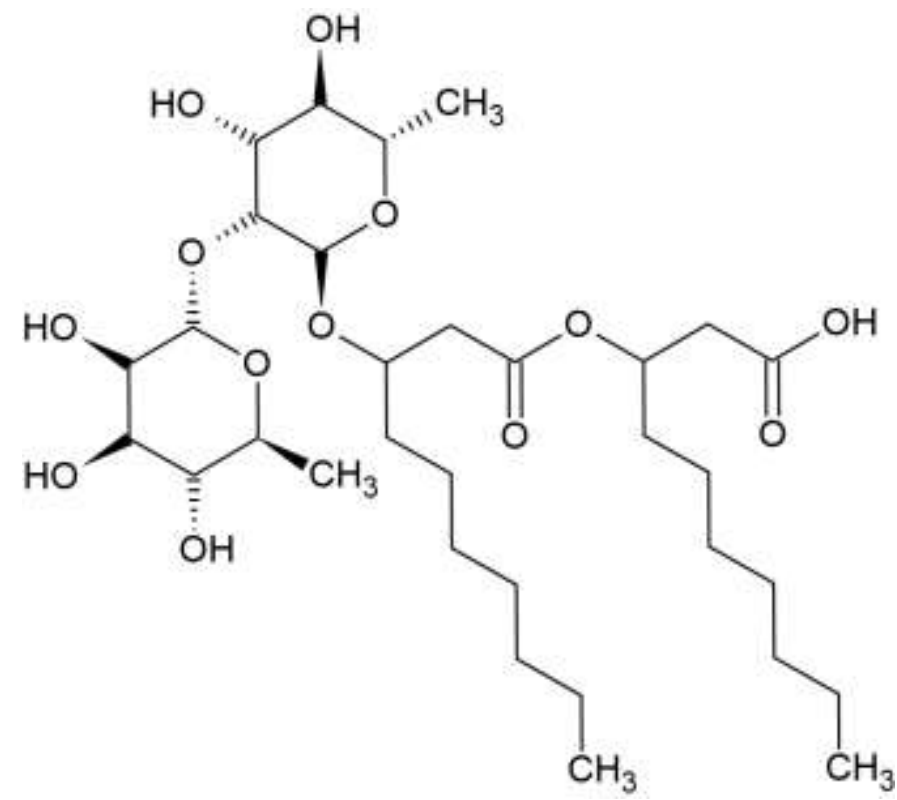

(b)

Figure 1. Molecule structure of mono-rhamnolipid (a) and di-rhamnolipid (b).

In this study, we report the expression of rhamnolipid in recombinant E. coli BL21(DE3) and isolated novel rhamnolipid congeners. A previous study [6-8] has succeeded in producing rhamnolipid in recombinant E. coli, but still low production yield $(0.07-0.64 \mathrm{~g} / \mathrm{L})$ with high-cost material production that using IPTG for T7 promoter induction. So we modified media production by using lactose as an inducer (autoinduction medium) [9] and an agricultural-waste namely palm oil mill effluent (POME)-based medium, which is abundant waste and high environmental impact problems in the palm oil industry in Indonesia [10]. POME has high glycerol and fatty acid contents [11], therefore, it may be used as a carbon source to convert lowvalue POME to high-value rhamnolipid.

This study aimed to characterize rhamnolipid expression in recombinant $E$. coli by determining rhamnolipid congeners and activity using high-resolution mass spectrometry (HRMS) and critical micelle concentration (CMC). We also optimize rhamnolipid production using the autoinduction medium and observe the addition of POME in recombinant $E$. coli. 


\section{MATERIAL AND METHODS}

\section{Bacterial strains, plasmids, and culture conditions}

Escherichia coli TOP10 (NEB, USA) and E. coli BL21 (DE3) (NEB, USA) was used as the heterologous host strain for the plasmids. The plasmid was derived from pUC57 plasmid (Genescript, USA) and inserted rhIAB (pPM RHLAB) and rhIABC sequences (pPM RHLABC). The strains were maintained on LB (Luria Bertani) agar medium at $37^{\circ} \mathrm{C}$ for $16 \mathrm{~h}$. Experiment were carried out in $250 \mathrm{~mL}$ Erlenmeyer flask with $50 \mathrm{~mL}$ of production media with following media: autoinduction medium (tryptone, $12 \mathrm{~g} / \mathrm{L}$; yeast extract, $24 \mathrm{~g} / \mathrm{L}$; $\left(\mathrm{NH}_{4}\right)_{2} \mathrm{SO}_{4}, 3.3 \mathrm{~g} / \mathrm{L} ; \mathrm{KH}_{2} \mathrm{PO}_{4}, 6.8 \mathrm{~g} / \mathrm{L} ; \mathrm{Na}_{2} \mathrm{HPO}_{4}, 7.1 \mathrm{~g} / \mathrm{L} ;$ glucose, $0.5 \mathrm{~g} / \mathrm{L} ;$ lactose, $2 \mathrm{~g} / \mathrm{L}, \mathrm{MgSO}_{4}, 0.15 \mathrm{~g} / \mathrm{L}$; trace elements, $0.03 \mathrm{~g} / \mathrm{L}$ ), $\mathrm{M} 9$ medium (M9 salt $\left(\mathrm{Na}_{2} \mathrm{HPO}_{4}, \mathrm{KH}_{2} \mathrm{PO}_{4}, \mathrm{NaCl}, \mathrm{NH}_{4} \mathrm{Cl}\right.$ ), $5.25 \mathrm{~g} / \mathrm{L} ; 1 \mathrm{M} \mathrm{MgSO}$, 1 $\mathrm{M} \mathrm{CaCl}_{2}$ ), LB (Luria Bertani) medium (tryptone, $10 \mathrm{~g} / \mathrm{L}$; yeast extract, $5 \mathrm{~g} / \mathrm{L} ; \mathrm{NaCl}, 10 \mathrm{~g} / \mathrm{L}$ ) and palm oil mill effluent/POME (Dermex Agro, Indonesia) mixed with M9 medium. The time and $\mathrm{pH}$ of the culture were optimized, and when appropriate, $0.5 \mathrm{mM}$ isopropyl- $\beta$-D-thiogalactoside (IPTG) and $1 \%(\mathrm{w} / \mathrm{v})$ lactose were added to induce the rhIABC gene. The antibiotic concentration used was ampicillin $\left(10^{5} \mathrm{ppm}\right)$.

\section{Plasmids construction design}

The $r h I A B$ gene was designed by positioning $r h I A$ (Acc. No: AAG06867), and $r$ IB (Acc. No: AAG06866) genes adjacent to each other with a $65 \mathrm{bp}$ nucleotide separating them. The tandem sequence was then ordered to be synthesized at Genescript, USA. The synthesized rhIAB gene was inserted into pUC57 as the backbone plasmid, containing the T7 lac promoter, RBS, CDS (rhIAB), rrnb T1 terminator, and T7 terminator, hereinafter referred to as PPM RHLAB. This plasmid constructed ( $P P M$ RHLAB) was a donation by the iGEM_ITB2015 team. The $r h / C$ gene sequence (Acc. No: AAG04519) was ordered to be synthesized at Macrogen Inc., South Korea, and codon optimization was performed using the GeneArt ${ }^{\circledR}$ GeneOptimizer tool for Escherichia coli. The synthetic $r h / C$ gene was equipped with the T7lac promoter, RBS, CDS (rh/C), and T7 terminator. This cassette was then sub-cloned into PPM RHLAB to create PPM RHLABC, which was facilitated by Sph1 and Hindll digestion.

PCR confirmation was carried out using GoTaq ${ }^{\circledR}$ Green Master Mix (Promega, USA). PCR confirmation was conducted with the specific primer of the $r h / A B$ sequence as follows: forward primer (5'GTTTCTTCGAATTCGCGGCCGCTTCTAG-3') and primer (5'GTTTCTTCCTGCAGCGGCCGCTACTAGTA-3') in 30 cycles of denaturation at $95{ }^{\circ} \mathrm{C}$, annealing at $54^{\circ} \mathrm{C}$, and extension at $72{ }^{\circ} \mathrm{C}$, while the specific primer of the $r h / C$ sequence as follows: forward primer (5'CTGCATGCGAAGCCAATACGAC-3') and reverse primer (5'-TACGCCAAGCTTTATAAACGCAG-3') in 30 cycles of denaturation at $95^{\circ} \mathrm{C}$, annealing at $57^{\circ} \mathrm{C}$, and extension at $72{ }^{\circ} \mathrm{C}$. The success of this cloning was confirmed by sequencing at Macrogen Inc., South Korea, and analyzed using SnapGeneTM v.4.3.10. The pPM RHLAB and pPM RHLABC plasmids were transformed into competent of $E$. coli TOP10 for cloning purposes and competent of $E$. coli strain BL21(DE3) for expression.

\section{Expression of rhamnolipid biosurfactant in recombinant E. coli}

A positive $E$. coli colony containing $\mathrm{PPM}$ RHLAB and $\mathrm{PPM}$ RHLABC was inoculated into a liquid culture of $5 \mathrm{~mL}$ LB medium. Five percent $(\mathrm{v} / \mathrm{v})$ of the overnight culture was inoculated into $50 \mathrm{~mL} \mathrm{LB}$ at $37^{\circ} \mathrm{C}$, with a shake at $250 \mathrm{rpm}$ for 2 - $4 \mathrm{~h}$. After $\mathrm{OD}_{600}$ reached to obtain $\mathrm{OD}_{600}$ of $0.5-0.7$, five $\mathrm{mL}$ of this culture was separated as non-induced culture, and then the other $45 \mathrm{~mL}$ was induced by $0.5 \mathrm{mM}$ IPTG (final concentration). After $20 \mathrm{~h}$, the culture was taken to extract rhamnolipid and characterized.

\section{Extraction of rhamnolipid from recombinant E. coli}

Extraction of mono-rhamnolipid (pPM RHLAB) and di-rhamnolipid (pPM RHLABC) by liquid extraction [12]. The culture was centrifuged for $15 \mathrm{~min}$ at $7000 \mathrm{~g}$ and $4{ }^{\circ} \mathrm{C}$. The supernatant was mixed with chloroform:ethanol (2:1), stirred for $5 \mathrm{~min}$ for equilibrium, and repeated for extraction twice. The organic phase was collected and evaporated the solvent by oven-drying and leaving a brown paste (rhamnolipid).

\section{Rhamnolipid congener diversity by HRMS and CMC determination}

Rhamnolipid extraction from pPM RHLAB and pPM RHLABC strains was characterized by highresolution mass spectrometry (HRMS), and the rhamnolipid activity was determined by critical micelle concentration (CMC) as well as surface tension. To determine of rhamnolipid congener diversity from E. coli BL21(DE3) pPM RHLAB and pPM RHLABC, each $10 \mathrm{mg}$ of rhamnolipid were dissolved into deuterated 
chloroform, and $100 \mu \mathrm{L}$ solution was injected for TOF-MS analysis in negative ion mode (LCT Premier XE Micromass, USA). The scanning mass spectrum ranged from $300 \mathrm{~m} / \mathrm{z}$ to $800 \mathrm{~m} / \mathrm{z}$. HRMS peaks were identified and analyzed based on [M-H] $\mathrm{m} / \mathrm{z}$ [2] to determine rhamnolipid congeners from $E$. coli pPM RHLAB and E. coli pPM RHLABC.

Each of the surfactant (sodium dodecyl sulfate/SDS as the positive control, mono-rhamnolipid, and dirhamnolipid) at $50 \mathrm{mg} / \mathrm{L}-2500 \mathrm{mg} / \mathrm{L}$ concentration was made to determine CMC value. The surface tension of each surfactant was measured until no reduction in surface tension for an added higher concentration of surfactants. The determination of CMC was measured using a Du-Nouy ring tensiometer (Surface Tensiomat ${ }^{\circledR}$ FISHER Model 21, USA). All of the experiments were conducted in triplicate, and the mean values \pm standard deviation were reported. The best rhamnolipid activity from recombinant strains ( $p P M$ $\mathrm{RHLAB}$ or PPM RHLABC) was selected and optimized the production by using autoinduction and POME media.

\section{Determination of the rhamnolipid production curve in recombinant $E$. coli}

The standard growth curve was first created as a reference to estimate the number of living colonies (colony form unit/cfu) on each OD value to calculate the cell number of recombinant $E$. coli. In this study, the method was used for creating the standard curve throughout OD $0.1-0.9$ and maintained on LB medium agar containing ampicillin antibiotics $\left(10^{5} \mathrm{ppm}\right)$ at $37^{\circ} \mathrm{C}$ for 16 hours. Colonies growing on each Petri dish were counted, and a regression curve was made.

The rhamnolipid production curve was carried out by sampling every $3 \mathrm{~h}$ of cultivation culture. A $5 \%(\mathrm{v} / \mathrm{v})$ pre-culture of recombinant $E$. coli was inoculated into $50 \mathrm{~mL}$ of the autoinduction medium and grown at $37^{\circ} \mathrm{C}$ at $250 \mathrm{rpm}$. The oil spreading test (OST) was performed to estimate the highest production time and rhamnolipid yield. The experiment was performed in triplicate, and the mean values \pm standard deviation were reported.

\section{Analysis of rhamnolipid concentration using oil spreading test (OST)}

The oil spreading test (OST) technique was used to analyze the surfactant activity qualitatively. The OST technique was carried out by adding $30 \mathrm{~mL}$ of water to a Petri dish (Area: $78.5 \mathrm{~cm}^{2}$ ) and adding $100 \mu \mathrm{L}$ of crude oil (from PT Pertamina, Mangunjaya refinery, South Sumatera). A supernatant containing the surfactant was dripped as much as $100 \mu \mathrm{L}$ at the midpoint of a Petri dish; as a result, an oil-spreading zone (OSZ) appeared [13]. The area of the OSZ was performed using the NIH ImageJ software [14] with the following formula:

$$
\text { Areaosz }=\text { AreadisH }\left(\text { Pixelosz } / \text { Pixel }{ }_{\text {DISH }}\right)
$$

Areaosz and Area ${ }_{\text {DISH }}$ are the areas of the circle of OSZ and the Petri dish $\left(78.5 \mathrm{~cm}^{2}\right)$, while Pixelosz and Pixel $_{\text {DISH }}$ are pixel measurements from the NIH ImageJ software, respectively. Determination of rhamnolipid concentration from recombinant $E$. coli fermentation culture was carried out using an oil spreading test technique on rhamnolipid standards. The rhamnolipid standard (AGAE Tech, USA) was used from $100 \mathrm{mg} / \mathrm{L}$ to $700 \mathrm{mg} / \mathrm{L}$. The Areaosz was obtained from the OST at each standard rhamnolipid standard concentration and formed a linear regression curve. The rhamnolipid standard curve was used to estimate the rhamnolipid concentration from recombinant $E$. coli cultures [15].

\section{Optimization of $\mathrm{pH}$ and temperature of rhamnolipid production in autoinduction medium and POME}

Optimization of rhamnolipid production from recombinant $E$. coli was carried out at variations of $\mathrm{pH} 4,7$ and 9 and temperatures of $30^{\circ} \mathrm{C}, 37^{\circ} \mathrm{C}$ and $40{ }^{\circ} \mathrm{C}$. Cultures were grown for optimal cultivation time, and subsequently, the supernatant was obtained and measured the concentration of rhamnolipid to show of Areaosz, and its value was interpolated by rhamnolipid standard regression. The experiment was performed in triplicate.

The optimal concentration of the POME-based medium was determined by the added variation of POME concentration (10\%, 15\%, 20\%, and 25\% (v/v)) in M9 medium. Induction was carried out with $1 \%(\mathrm{w} / \mathrm{v})$ lactose when the culture OD reached 0.6. Cultures were grown at the optimal cultivation time, temperature, and $\mathrm{pH}$ of rhamnolipid production. The supernatant was obtained and measured the concentration of rhamnolipid to show of Areaosz, and the value was interpolated by rhamnolipid standard regression. The experiment was performed in triplicate. 


\section{RESULTS}

\section{Plasmid construction design of rhamnolipid expression}

The size of the $r h I A B$ part was $2551 \mathrm{bp}$, and the $r h / C$ part was $1129 \mathrm{bp}$ (Figure 2). This size was also confirmed by PCR confirmation with the specific primers of $r h I A B$ and $r h / C$ parts (Figure 3 ).

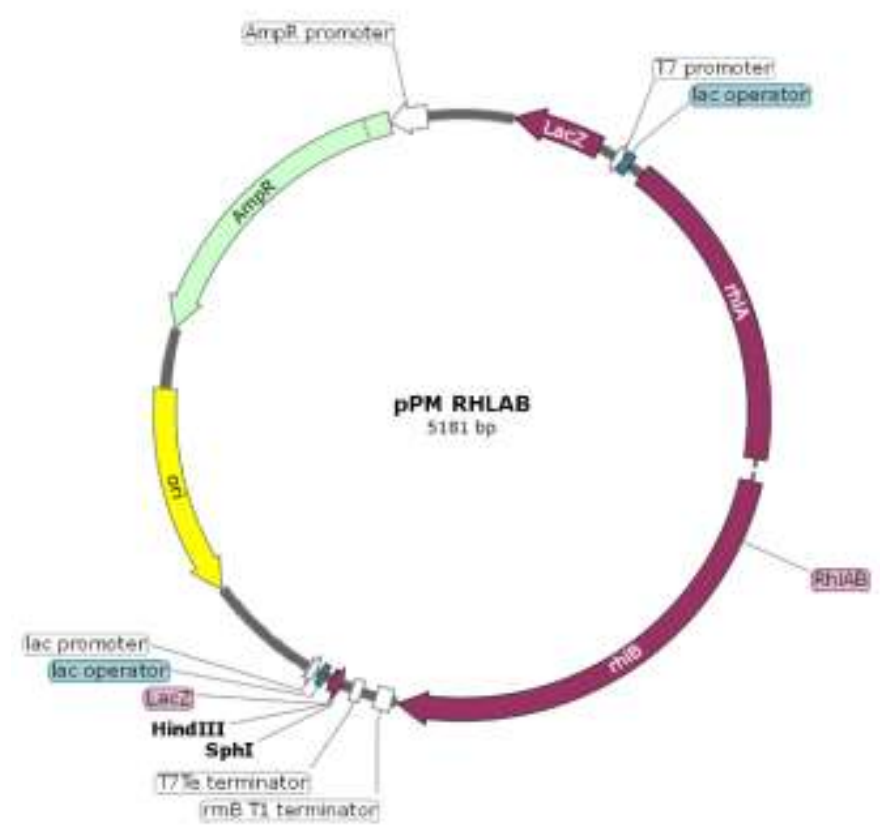

(a)

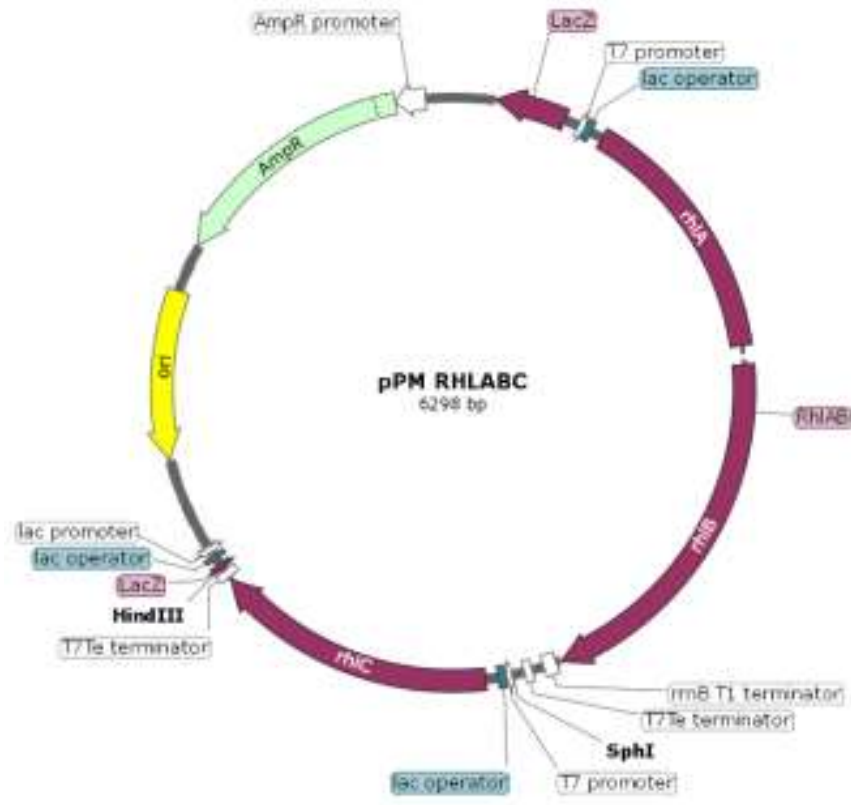

(b)

Figure 2. $p P M$ RHLAB (a) and pPM RHLABC (b) construction map.

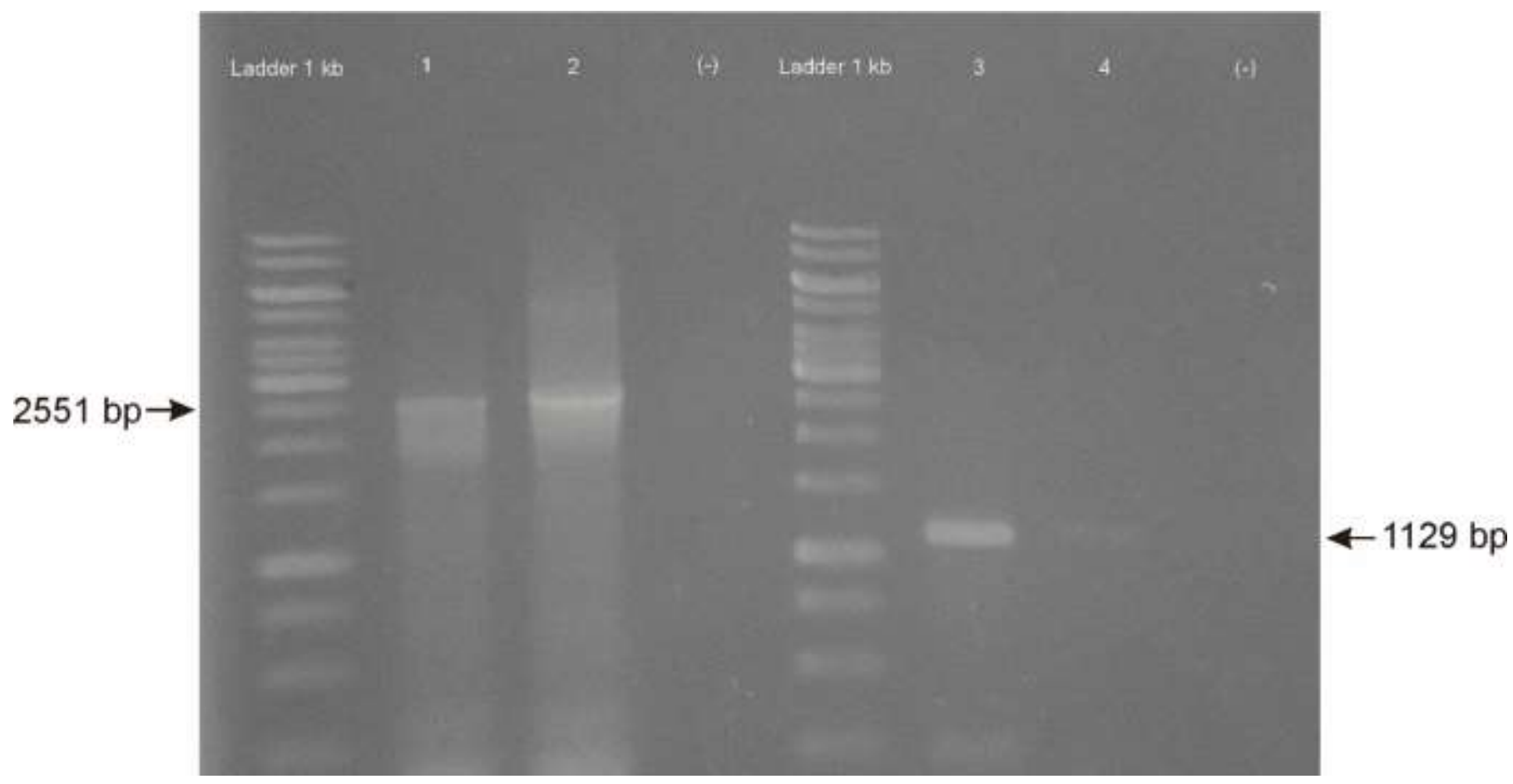

Figure 3. PCR confirmation of pPM RHLAB (1) and pPM RHLABC (2) using specific primers for $r$ IhIA and $r h / B$ genes and PCR confirmation of RHLABC ( 3 and 4$)$ with the specific primer rhlC gene. (-) is the negative control.

Figure 2 shows that both parts have the same promoter and terminator, namely T7lac promoter, and T7 terminator. However, pPM RHLAB has an additional terminator, which is the rrnb T1 terminator. The rh/C gene was driven by a separate promoter from the rhIAB gene. PCR confirmation of pPM RHLAB and pPM RHLABC (Figure 3) confirmed that both recombinant strains consisted of desired genes ( $r h / A B$ and $r h / C$ ). 
Therefore, it can be concluded that both plasmids were successfully transformed into E. coli BL21(DE3) and continued for rhamnolipid expression and characterization.

\section{Characterization of rhamnolipid expression by HRMS and determination of CMC}

\section{Characterization of rhamnolipid expression by HRMS}

HRMS analysis aims to confirm rhamnolipid congeners expressed by $E$. coli PPM RHLAB and pPM RHLABC. Peaks of HRMS (Figure 4) from both rhamnolipid products were analyzed and compared to the rhamnolipid diversity database, which has been reported by Abdel-mawgoud [2]. Table 1 and Table 2 show rhamnolipid congeners from rhamnolipid of $E$. coli $\mathrm{PPM}$ RHLAB and $\mathrm{pPM}$ RHLABC.

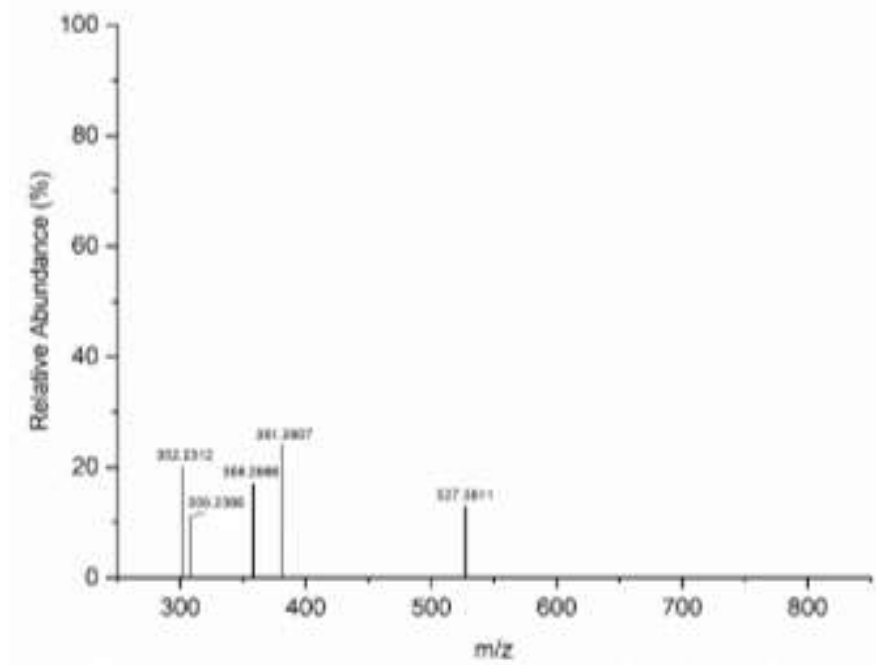

(a)

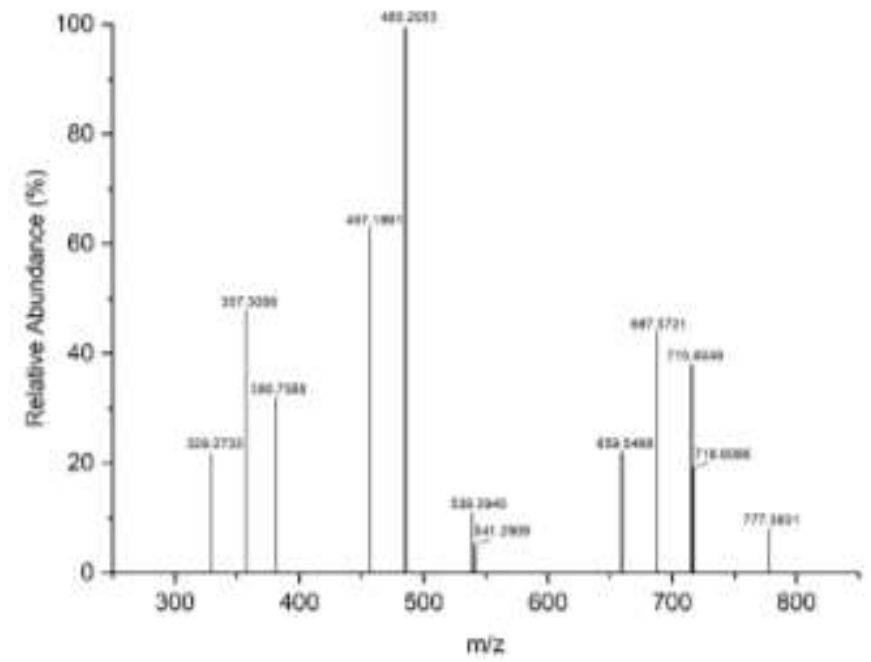

(b)

Figure 4. HRMS spectra of the rhamnolipids produced by $E$. coli pPM RHLAB (a) and E. coli pPM RHLABC. The $X$ and $Y$-axes indicate $\mathrm{m} / \mathrm{z}$ (mass-to-charge ratio) and intensity/relative abundance (\%), respectively.

Table 1. Relative abundance of main rhamnolipid congeners produced by recombinant E. coli pPM RHLAB by HRMS.

\begin{tabular}{|c|c|c|c|}
\hline Rhamnolipid congeners & M. Form & {$[\mathrm{M}-\mathrm{H}]^{-} \mathbf{m} / \mathbf{z}$} & $\begin{array}{l}\text { Relative abundance } \\
(\%)\end{array}$ \\
\hline \multicolumn{4}{|l|}{ Mono-rhamnolipid } \\
\hline Rha- $\mathrm{C}_{8: 2}$ & $\mathrm{C}_{14} \mathrm{H}_{22} \mathrm{O}_{7}$ & 302.2312 & 20 \\
\hline Rha- $\mathrm{C}_{8}$ & $\mathrm{C}_{14} \mathrm{H}_{36} \mathrm{O}_{7}$ & 308.2386 & 11 \\
\hline Rha- $C_{12: 2}$ & $\mathrm{C}_{18} \mathrm{H}_{30} \mathrm{O}_{7}$ & 358.2986 & 17 \\
\hline Rha- $\mathrm{C}_{14: 2}$ & $\mathrm{C}_{20} \mathrm{H}_{34} \mathrm{O}_{7}$ & 381.2907 & 24 \\
\hline Rha- $\mathrm{C}_{10}-\mathrm{C}_{12: 1}$ & $\mathrm{C}_{28} \mathrm{H}_{46} \mathrm{O}_{9}$ & 527.3611 & 13 \\
\hline
\end{tabular}

Table 2. Relative abundance of main rhamnolipid congeners produced by recombinant $E$. coli pPM RHLABC by HRMS.

\begin{tabular}{|c|c|c|c|}
\hline Rhamnolipid congeners & M. Form & {$[\mathrm{M}-\mathrm{H}]^{-} \mathrm{m} / \mathbf{z}$} & Relative abundance (\%) \\
\hline \multicolumn{4}{|l|}{ Mono-rhamnolipid } \\
\hline${ }^{1}$ Rha $-C_{10: 2}$ & $\mathrm{C}_{16} \mathrm{H}_{26} \mathrm{O}_{7}$ & 329.2733 & 21.7 \\
\hline Rha- $\mathrm{C}_{12: 2}$ & $\mathrm{C}_{18} \mathrm{H}_{30} \mathrm{O}_{7}$ & 357.3086 & 48 \\
\hline Rha- $C_{14: 2}$ & $\mathrm{C}_{20} \mathrm{H}_{34} \mathrm{O}_{7}$ & 380.7588 & 32 \\
\hline${ }^{1}$ Rha $-C_{10}-C_{13: 2}$ & $\mathrm{C}_{29} \mathrm{H}_{52} \mathrm{O}_{9}$ & 539.2943 & 11 \\
\hline${ }^{1}$ Rha $-\mathrm{C}_{10}-\mathrm{C}_{13: 1}$ & $\mathrm{C}_{29} \mathrm{H}_{54} \mathrm{O}_{9}$ & 541.2909 & 5 \\
\hline Di-rhamnolipid & & & \\
\hline Rha-Rha- $\mathrm{C}_{8}^{\prime}$ & $\mathrm{C}_{20} \mathrm{H}_{36} \mathrm{O}_{7}$ & 457.1891 & 63 \\
\hline Rha-Rha- ${ }_{10}$ & $\mathrm{C}_{22} \mathrm{H}_{40} \mathrm{O}_{11}$ & 485.2053 & 99.5 \\
\hline${ }^{1}$ Rha-Rha- $\mathrm{C}_{10}-\mathrm{C}_{11: 2}$ & $\mathrm{C}_{33} \mathrm{H}_{52} \mathrm{O}_{13}$ & 659.5488 & 22 \\
\hline${ }^{1}$ Rha-Rha- $\mathrm{C}_{12}-\mathrm{C}_{11: 2}$ & $\mathrm{C}_{35} \mathrm{H}_{60} \mathrm{O}_{13}$ & 687.5721 & 44 \\
\hline${ }^{1}$ Rha-Rha- $\mathrm{C}_{12}-\mathrm{C}_{13: 2}$ & $\mathrm{C}_{38} \mathrm{H}_{64} \mathrm{O}_{13}$ & 715.6049 & 38 \\
\hline${ }^{1}$ Rha-Rha- $\mathrm{C}_{13: 2}-\mathrm{C}_{12}$ & $\mathrm{C}_{38} \mathrm{H}_{64} \mathrm{O}_{13}$ & 716.6086 & 19 \\
\hline${ }^{1}$ Rha-Rha- $\mathrm{C}_{14}-\mathrm{C}_{15}$ & $\mathrm{C}_{41} \mathrm{H}_{78} \mathrm{O}_{13}$ & 777.3831 & 8 \\
\hline
\end{tabular}

${ }^{1}$ Novel rhamnolipid congeners produced by E. coli pPM RHLABC 
High-resolution mass spectrometry (HRMS) results show that rhamnolipid from recombinant $E$. coli pPM $\mathrm{RHLAB}$ consist of five rhamnolipid congeners and rhamnolipid from E. coli pPM RHLABC consists of 12 rhamnolipid congeners. Furthermore, E. coli pPM RHLAB produced mono-rhamnolipid congeners, namely Rha- $\mathrm{C}_{14: 2}$ with higher relative abundance $(24 \%)$ and $\mathrm{Rha}-\mathrm{C}_{8}$ with lower relative abundance $(11 \%)$. In comparison, the $E$. coli pPM RHLABC produced di-rhamno mono-lipid (Rha-Rha- $\mathrm{C}_{10}$ ) with higher relative abundance (99.5\%) and mono-rhamno di-lipid (Rha- $\left.\mathrm{C}_{10}-\mathrm{C}_{13: 1}\right)$ with lower relative abundance $(5 \%)$. Therefore, it can be concluded that $E$. coli pPM RHLAB only produces mono-rhamnolipid (by expression of $r h I A$, and $r h / B$ genes) and E. coli pPM RHLABC can produce both mono-rhamnolipid and di-rhamnolipid (by expression of $r h / A$, $r h / B$, and $r h / C$ genes).

In this stimulated high-resolution mass spectrometry, the ion of Rha- $\mathrm{C}_{14: 2}$ has the highest relative abundance and peak among the other of mono-rhamnolipid congeners, so Rha- $\mathrm{C}_{14: 2}$ was the base peak of rhamnolipid produced by E. coli pPM RHLAB. However, in the di-rhamnolipid congeners, Rha-Rha- $\mathrm{C}_{10}$ has the highest relative abundance and peak among the other of rhamnolipid congeners (mono- or di- types), so Rha-Rha- $\mathrm{C}_{10}$ was the base peak of rhamnolipid produced by $E$. coli pPM RHLABC. In the interpreting of HRMS result, for instance, Rha-Rha- $\mathrm{C}_{8}$ has a relative abundance of $63 \%$, meaning the mass spectrum contains $63 \%$ as many ions of $m / z$ Rha-Rha- $\mathrm{C}_{10}$ (the base peaks). Note that this does not mean $99.5 \%$ of the ions produced have $m / z=$ Rha-Rha- $\mathrm{C}_{10}$ and another $63 \%$ have $m / z=$ Rha-Rha- $\mathrm{C}_{8}$, because it was not possible to produce more than $100 \%$.

Tables 1 and 2 show that recombinant E. coli pPM RHLABC produces novel rhamnolipid congeners that different congeners have been reported, but it was not from E. coli pPM RHLAB [2]. The novel rhamnolipid congeners from $E$. coli pPM RHLABC consist of mono-rhamno mono-lipid (Rha- $\mathrm{C}_{10: 2}$ ), mono-rhamno di-lipid (Rha- $\mathrm{C}_{10}-\mathrm{C}_{13: 2}$ and Rha- $\mathrm{C}_{10}-\mathrm{C}_{13: 1}$ ), and di-rhamno di-lipid (Rha-Rha- $\mathrm{C}_{10}-\mathrm{C}_{11: 2}$, Rha-Rha- $\mathrm{C}_{12}-\mathrm{C}_{11: 2}$, Rha-Rha$\mathrm{C}_{12}-\mathrm{C}_{13: 2}$, Rha-Rha- $\mathrm{C}_{13: 2}-\mathrm{C}_{12}$ and Rha-Rha- $\left.\mathrm{C}_{14}-\mathrm{C}_{15}\right)$.

\section{Determination of rhamnolipid CMC from recombinant E. coli}

The best biosurfactant activity has a lower surface tension (ST) value and critical micelle concentration $(\mathrm{CMC})$. The critical micelle concentration $(\mathrm{CMC})$ is the minimum concentration required to form micelles and is defined by the surface tension of various surfactant concentrations. Rhamnolipid from E. coli pPM RHLAB and PPM RHLABC showed different values of CMC (Figure 5).

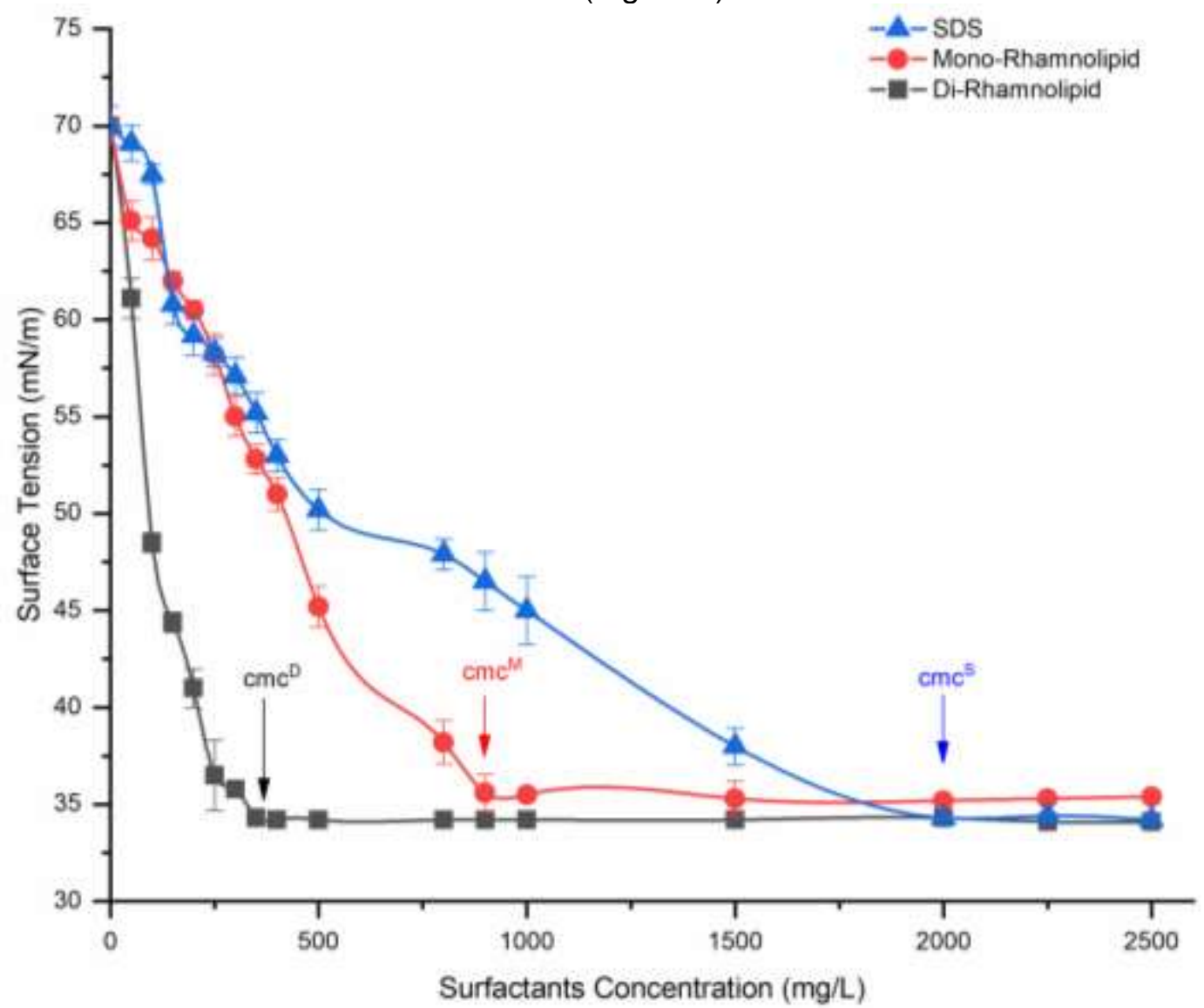

Figure 5. Critical micelle concentration (CMC) of SDS (sodium dodecyl sulfate), mono-rhamnolipid, and di-rhamnolipid. $\mathrm{cmc}^{\mathrm{S}}, \mathrm{cmc}^{\mathrm{M}}$, and $\mathrm{cmc}^{\mathrm{D}}$ are the values of $\mathrm{CMC}$ for SDS, mono-rhamnolipid, and di-rhamnolipid, respectively. 
Figure 5 shows that di-rhamnolipid has the lowest CMC value $(300 \mathrm{mg} / \mathrm{L})$ with a surface tension value of $34.3 \mathrm{mN} / \mathrm{m}$ than mono-rhamnolipid (900 $\mathrm{mg} / \mathrm{L} \mathrm{CMC}$ value and $35.4 \mathrm{mN} / \mathrm{m}$ surface tension value). Whereas, sodium dodecyl sulfate had the highest CMC value $(2000 \mathrm{mg} / \mathrm{L})$ with a surface tension value of $34.2 \mathrm{mN} / \mathrm{m}$ than both biosurfactants. Because di-rhamnolipid from E. coli pPM RHLABC has lower surface tension and CMC, E. colipPM RHLABC was continued to optimize production by using autoinduction medium and POMEbased medium.

\section{Optimization of rhamnolipid production from recombinant $E$. coli in autoinduction medium}

The culture duration and physiological conditions for biosurfactant production were essential to optimize for the determination of optimal conditions. Figure 6a shows the rhamnolipid production curve in recombinant E. coli using the autoinduction medium. Optimal production of rhamnolipid can be considered on the production curve at $20 \mathrm{~h}$ culture time with Areaosz of $48.3 \mathrm{~cm}^{2}$. The optimal culture time of $20 \mathrm{~h}$ lies in the stationary phase of recombinant $E$. coli.

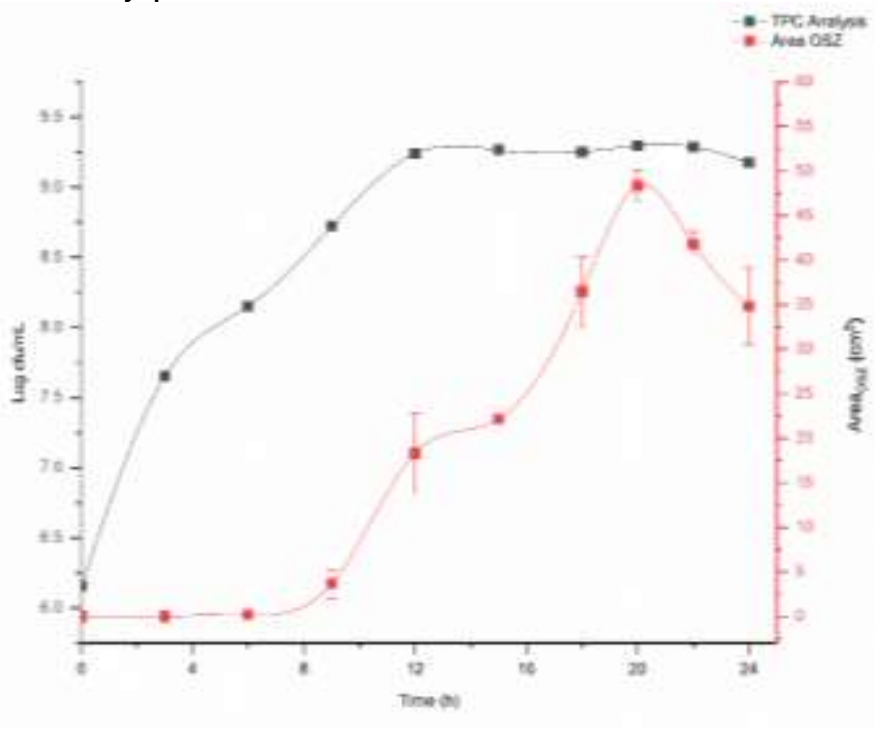

(a)

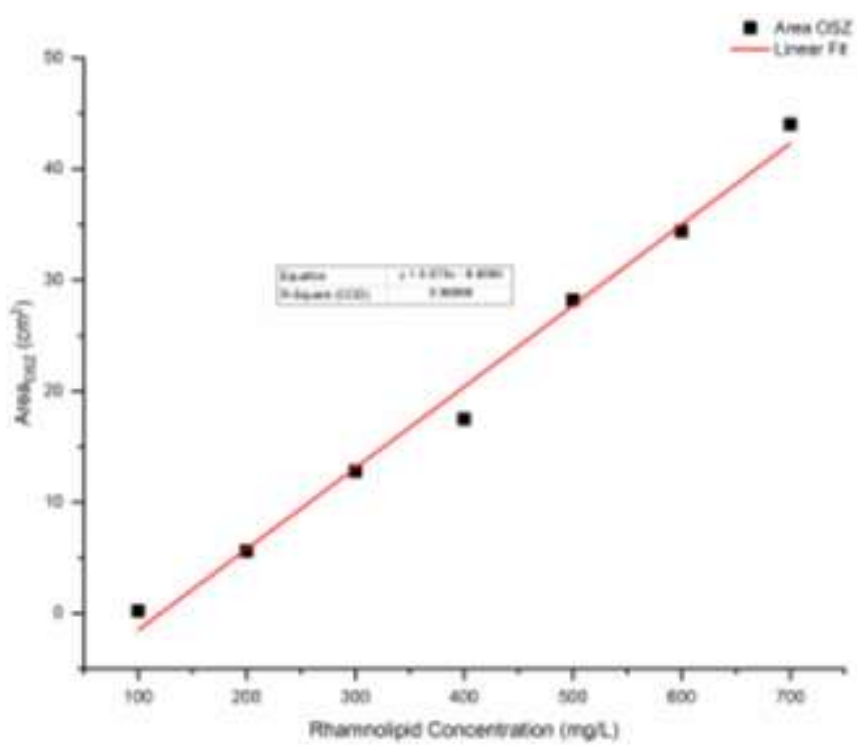

(b)

Figure 6. Rhamnolipid production from recombinant $E$. coli in autoinduction medium. TPC analysis is the total plate count is counted in cfu/mL, and area OSZ is the area from the oil spreading test.

Based on Figure 6a, rhamnolipid was early expressed at $9 \mathrm{~h}$ of cultivation time with an Areaosz of 3.8 $\mathrm{cm}^{2}$, but still with a deficient concentration. Production of rhamnolipid begins to be fully expressed at the end of the log phase, and the optimal time was $20 \mathrm{~h}$. However, at the end of the stationary phase (exceed the optimal time), rhamnolipid expression decreased due to enter the cell death phase and the accumulation of toxic substances. On the other sides, the precursor of RhIB (L-rhamnose) may be declined after the optimal time and mainly produced HAA (the expression of $r h / A$ ), which lower of surface tension and Areaosz than rhamnolipid.

We determined rhamnolipid concentration in culture supernatant from recombinant $E$. coli culture using oil spreading test and obtained the rhamnolipid standard curve equation; $y=0.073 x-8.8094 ; R^{2}=0.99$, which $x=$ rhamnolipid concentration and $y=$ Areaosz (Figure $6 b$ ). Figure $6 b$ shows that there was a positive correlation between Areaosz and rhamnolipid concentration; therefore, this method can be applied to estimated rhamnolipid concentrations more accurately than using the staining method, such as anthrone or orcinol reagent, with a spectrophotometer due to overestimating result of rhamnolipid yield measured [15].

Rhamnolipid production in the wild type, e.g., Pseudomonas aeruginosa, it was dependent on $\mathrm{pH}$ and temperature. Hence, we considered observing $\mathrm{pH}$ and temperature effects of rhamnolipid production in recombinant $E$. coli. Based on Figure 7 shows that the optimal rhamnolipid production lies at $37^{\circ} \mathrm{C}$ with rhamnolipid concentrations reaching $1245 \pm 142.49 \mathrm{mg} / \mathrm{L}$ compared to temperatures of $30{ }^{\circ} \mathrm{C}(516 \pm 66.12$ $\mathrm{mg} / \mathrm{L})$, and $40{ }^{\circ} \mathrm{C}(130 \pm 7.50 \mathrm{mg} / \mathrm{L})$. The optimum $\mathrm{pH}$ was found at $\mathrm{pH} 7$, with a similar quantity produced at $37^{\circ} \mathrm{C}$. However, changing the $\mathrm{pH}$ value affects of rhamnolipid yield with at $\mathrm{pH} 5$ and $\mathrm{pH} 9$ was $499 \pm 113.20$ $\mathrm{mg} / \mathrm{L}$, and $389 \pm 68.10 \mathrm{mg} / \mathrm{L}$, respectively. 


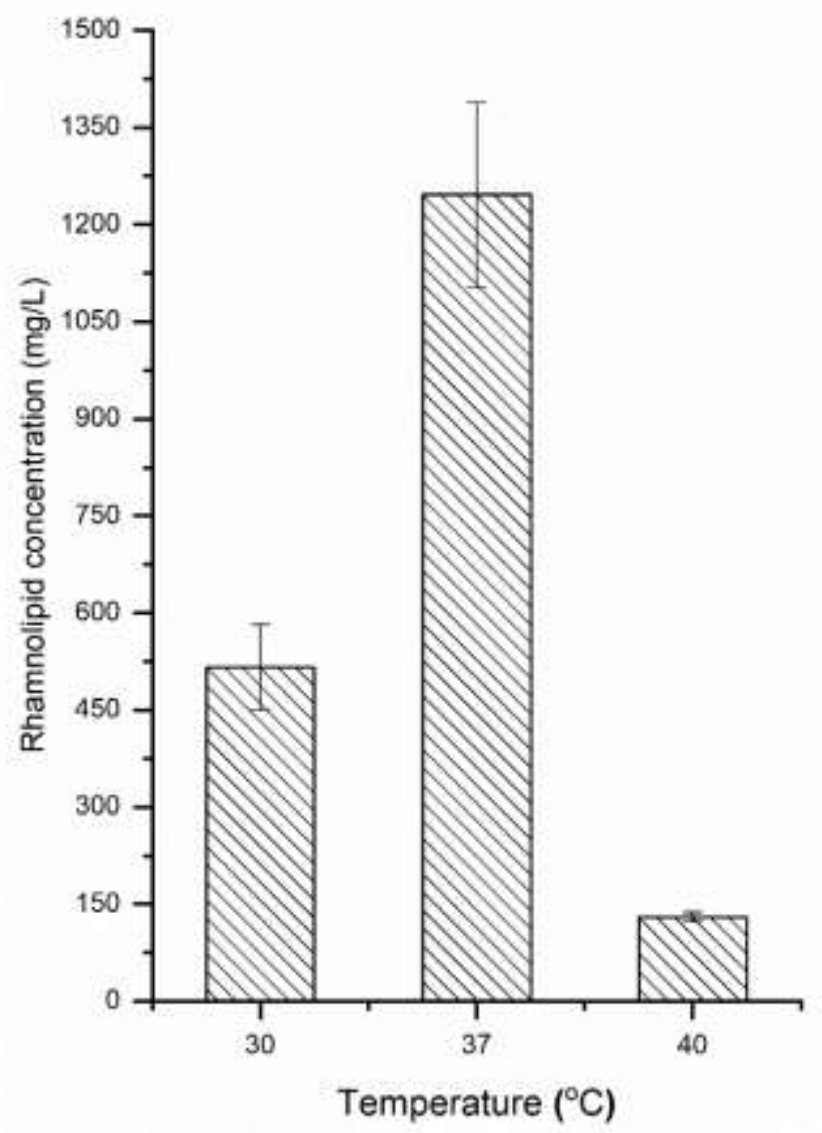

(a)

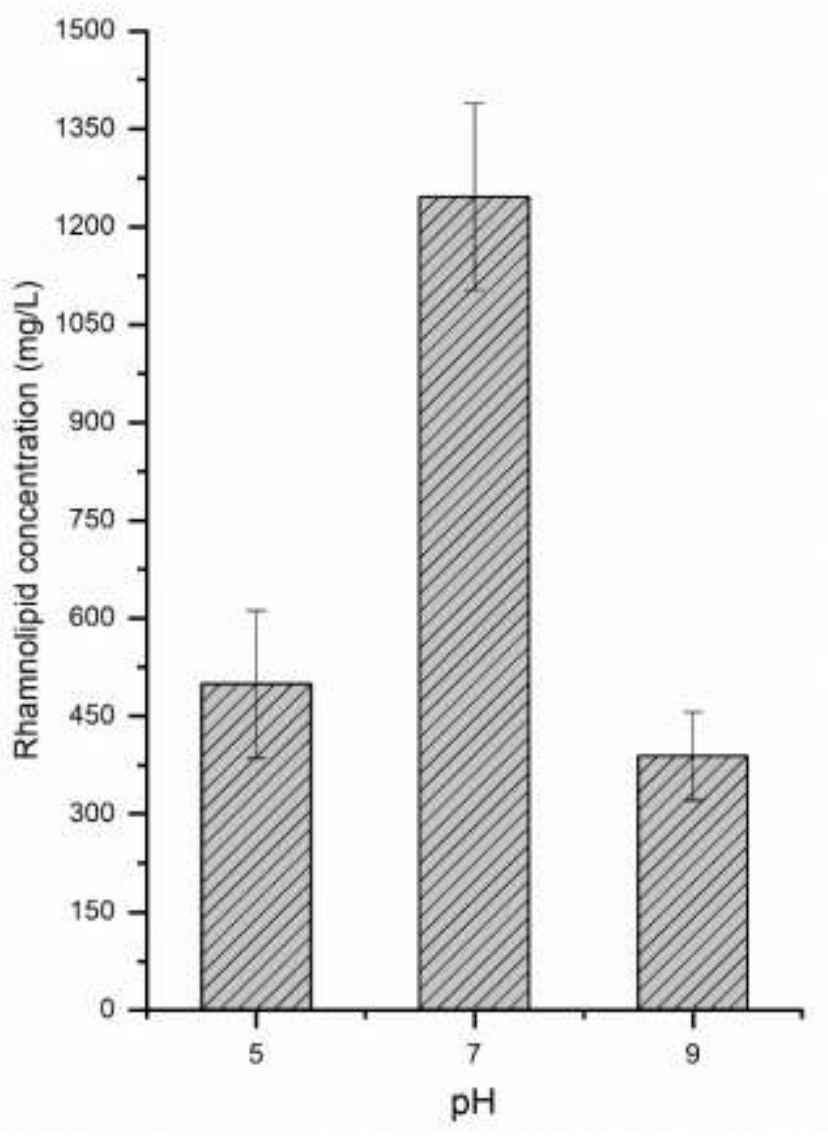

(b)

Figure 7.Optimization of rhamnolipid production from recombinant $E$. coli at variations of temperatures and $\mathrm{pH}$. The values are mean \pm S.D of triplicate analyses

\section{Optimization of rhamnolipid production in palm oil mill effluent (POME) medium}

In this study, we optimized the POME concentration as an economical medium in recombinant $E$. coli to produce rhamnolipid. POME was mixed with $\mathrm{M} 9$ medium as a source of $\mathrm{pH}$ buffer and nitrogen sources. The culture in this medium was induced by $1 \%(\mathrm{w} / \mathrm{v})$ lactose, which optimal lactose concentration to induce T7lac promoter in recombinant E. coli [17]. Based on Figure 8, the highest concentration of POME medium was obtained at a concentration of $20 \%(\mathrm{v} / \mathrm{v})(318.42 \pm 35.12 \mathrm{mg} / \mathrm{L})$, while the lowest concentration was obtained at a concentration of $25 \%(\mathrm{v} / \mathrm{v})(180.40 \pm 32.31 \mathrm{mg} / \mathrm{L})$. In comparison, at a concentration of $10 \%(\mathrm{v} / \mathrm{v})$ and $15 \%(\mathrm{v} / \mathrm{v})$ was $211.58 \pm 24.5 \mathrm{mg} / \mathrm{L}$ and $305.59 \pm 11.29 \mathrm{mg} / \mathrm{L}$, respectively. However, we found that the optimal range of POME concentration was $15 \%-20 \%(\mathrm{v} / \mathrm{v})$. 


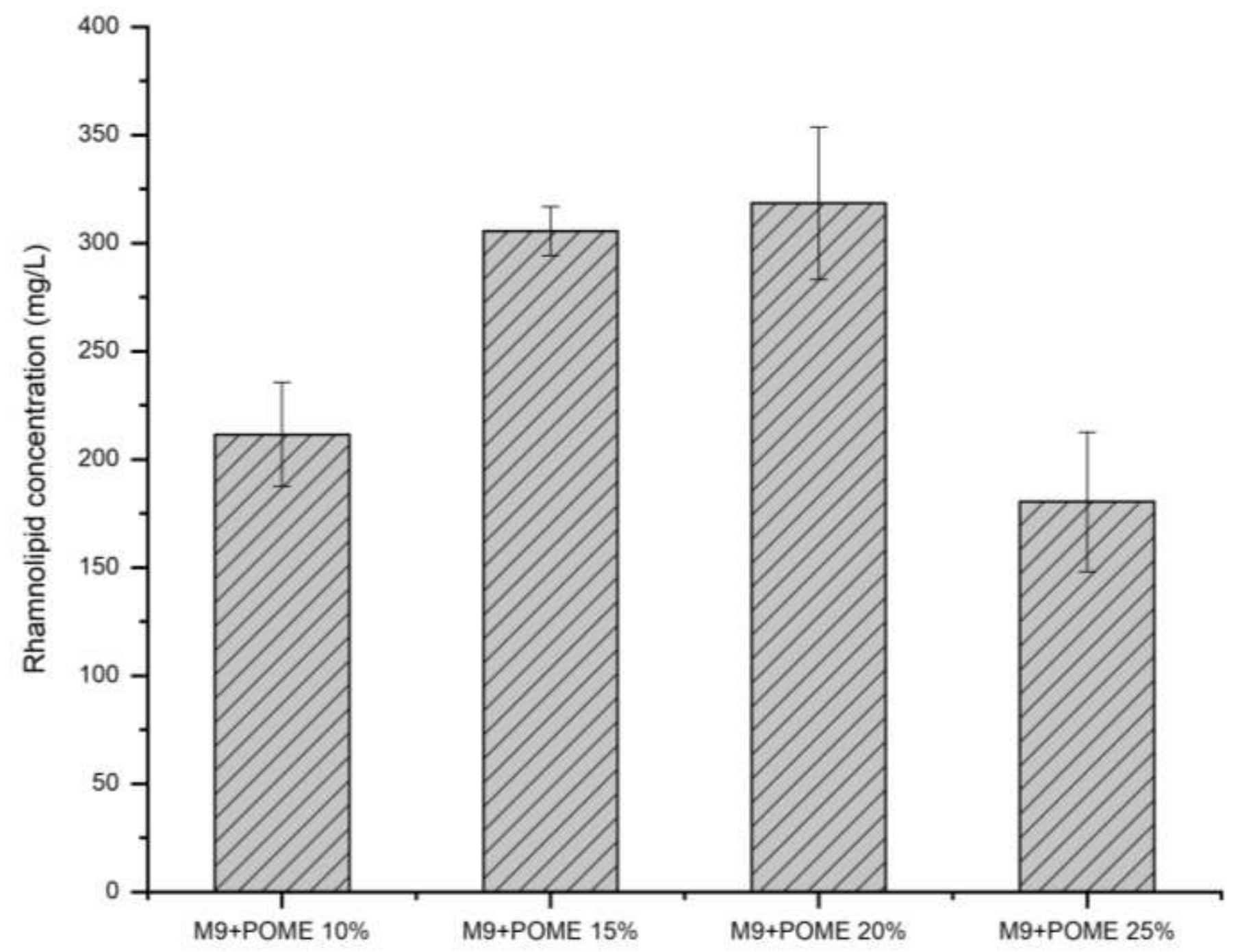

POME concentration (\%)

Figure 8. Optimization of rhamnolipid production from recombinant E. coli in POME-based medium. The values are mean \pm S.D of triplicate analyses.

\section{DISCUSSION}

Rhamnolipid is a biodegradable surfactant, which is extensively used in industrial and enviromental application such as the pharmaceutical, food industries, and enhances oil recovery [18]. In this study, we transformed the rhamnolipid gene by synthetic approach from Pseudomonas aeruginosa, which is pathogenic bacterium, into a GRAS (generally recognized as safe) strain, such as Escherichia coli. The rhIABC gene was driven by the T7lac promoter to increase synthesis of rhamnolipid. However, the rh/C gene was driven by a separate T7lac promoter from the $r$ hlAB gene. They consist of two separate operons that mimic the two natural operons in Pseudomonas aeruginosa [16]. In $P$. aeruginosa, the $r h / A$ and $r h / B$ genes are arranged in an operon adjacent to $r h I R l$, a regulator that plays a role in quorum sensing whereas the $r h / C$ gene was located at a distance far away from the rhIAB operon (PA1131 locus), which has no promoter part in the upstream section [19].

To investigate the composition of rhamnolipid congeners by $E$. coli pPM RHLAB and pPM RHLABC whether both plasmids encode mono-rhamnolipid or di-rhamnolipid, each of the rhamnolipids extractions were subjected to HRMS analysis. We found that E. coli pPM RHLAB only encodes mono-rhamnolipid, and E. coli pPM RHLABC may encode mono-rhamnolipid and di-rhamnolipid. However, rhamnolipid congeners by $P$. aeruginosa mainly consist of Rha- $C_{10}$ and Rha-Rha- $C_{10}-C_{10}$ [13], but our recombinant strain mainly produces Rha- $\mathrm{C}_{12: 2}$ (mono-rhamnolipid) and Rha-Rha- $\mathrm{C}_{10}$ (di-rhamnolipid). The difference in rhamnolipid congeners may be caused by various factors such as strains, carbon sources, and culture conditions [20]. Additionally, it influences rhamnolipid activity, which di-rhamnolipid facilitates a decrease in surface tension 
values [21]. Furthermore, in the analysis of critical micelle concentration (CMC), we found that di-rhamnolipid have lower CMC values and surface tension value compared to mono-rhamnolipid and SDS (sodium dodecyl sulfate) as synthetic/chemical surfactants. Mono-rhamnolipid is less soluble and adsorbed to surfaces more strongly, requiring higher CMC for the solubilization of hydrocarbons than di-rhamnolipid [22]. Because dirhamnolipid has lower CMC, di-rhamnolipid has more activities and efficiency than mono-rhamnolipid [19,23]. Further, we optimized di-rhamnolipid production from E. coli pPM RHLABC using autoinduction and POME media.

The rhamnolipid production in recombinant $E$. coli using autoinduction medium was inspired by the research of Studier [9], where the production of rhamnolipid itself was not induced by IPTG, but by lactose. This is because IPTG is expensive and not suitable for later to continue on an industrial application. Using the autoinduction medium allows more optimal production of rhamnolipid without knowing specific OD values in the induction process (as was carried out in expressions with the IPTG inducer). Growth of recombinant $E$. coli using autoinduction medium may use glucose as a primary carbon source until glucose depletes in the mid to late-log phase, and lactose will be used as a second carbon source while inducing T7 lac promoter [9], so the expression of the $r h I A B C$ gene can occur. The glucose and lactose content in autoinduction medium may also increase rhamnolipid yield production. This is because glucose as a source in the formation of rhamnose in rhamnolipid biosynthesis [24]. This autoinduction medium itself has been previously used in protein expression but has never been conducted in rhamnolipid expression from wild-type or recombinant strains. Previous research on rhamnolipid production from recombinant $E$. coli still uses LB medium and was induced with IPTG $[6,8,25]$. The use of autoinduction medium is a novelty for producing high yield rhamnolipid in recombinant $E$. coli.

In $P$. aeruginosa, the wild-type rhamnolipid production strain, the best rhamnolipid production was in the range of $25-37^{\circ} \mathrm{C}$, and the best $\mathrm{pH}$ was in the range of $6-6.8$, whereas above $42{ }^{\circ} \mathrm{C}$ and $\mathrm{pH} 7$ decreased rhamnolipid production [26]. Similarly, we found that rhamnolipid production in recombinant $E$. coli was optimum at $37^{\circ} \mathrm{C}$ and $\mathrm{pH} 7$ using autoinduction medium. $P$. aeruginosa and $E$. coli may live inside the human body therefore the human body temperature of $37^{\circ} \mathrm{C}$ and $\mathrm{pH} 7$ will be comfortable for both microorganisms. Interestingly, for $24 \mathrm{~h}$ of cultivation time, our rhamnolipid yield in recombinant $E$. coli, which harboring $\mathrm{pPM}$ $\mathrm{RHLABC}$, by using autoinduction medium was higher $(1245 \mathrm{mg} / \mathrm{L})$ than from $P$. aeruginosa $(206 \mathrm{mg} / \mathrm{L})$ [7], and other recombinant strains that have been reported, such as E. coli HB101 (pINC94-rhAB), E. coli BL21(DE3) (ETRABC-rhIABC), and E. coli BL21(DE3) (DJ208-rhIABC) were $70.5 \mathrm{mg} / \mathrm{L}, 120 \mathrm{mg} / \mathrm{L}$, and 640 $\mathrm{mg} / \mathrm{L}$, respectively [6-8]. As a result, it is very promising for further bioprocessing of our recombinant strain to enhance large-scale production.

To investigate the addition of POME in fermentation culture, variations of POME concentration were observed. We found that the optimal concentration was $20 \%(\mathrm{v} / \mathrm{v})$ in POME addition. POME is an agricultural waste with high BOD and COD content, so the addition of POME exceeding $20 \%(\mathrm{v} / \mathrm{v})$ may cause nonoptimal bacterial growth and decreased rhamnolipid production. Analysis of POME by GC-MS shows that it contains complex compounds, including glycerol, fatty acids, and other organic compounds with a glycerol content of $49 \%$ [11] therefore, it can be used by recombinant E. coli as a substrate to produce rhamnolipid. Glycerol can be converted to lipid precursor for rhamnolipid production as a carbon source by the respiratory metabolism pathway of glycerol in E. coli. In this way, glycerol may be converted to acetyl-CoA, which entered to FAS II (fatty acid synthase type-II) pathway and produce HAA as the precursor of RhIA [2]. Production of rhamnolipid using POME medium has been carried out previously in Pseudomonas aeruginosa [27] and $P$. stutzeri [11] but has never been carried out in recombinant $E$. coli. Using POME medium is expected to be used for further economic rhamnolipid production. However, the rhamnolipid yield using POME was lower than using autoinduction medium. It may be considered for further by using POME in the M9 medium with the addition of glucose as a rhamnose substrate to enhance rhamnolipid yield production.

\section{CONCLUSION}

Escherichia coli BL21(DE3) recombinant was able produced mono-rhamnolipid (pPM RHLAB) and dirhamnolipid (pPM RHLABC). The size of $r h I A B$ part was $2551 \mathrm{bp}$ and $r h / C$ part was $1129 \mathrm{bp}$, which was regulated by T7lac promoters and T7 terminators. The properties of biosurfactants show that di-rhamnolipid have the lowest surface tension and CMC than mono-rhamnolipid and synthetic surfactant (SDS). HRMS analysis of rhamnolipid extraction shows that recombinant E. coli pPM RHLAB mainly produced monorhamnolipid (Rha- $\mathrm{C}_{14: 2}$ ) while E. coli pPM RHLABC strain mainly produced di-rhamnolipid (Rha-Rha- $\left.\mathrm{C}_{10}\right)$. In this study, rhamnolipid production using the autoinduction medium was relatively higher than other systems known today in recombinant Escherichia coli. The best rhamnolipid production was found at $20 \mathrm{~h}$ cultivation 
time, temperature $37{ }^{\circ} \mathrm{C}, \mathrm{pH} 7$ with Areaosz of $48.3 \mathrm{~cm}^{2}$. The POME medium successfully produced rhamnolipid with an optimal addition of POME of $20 \%(\mathrm{v} / \mathrm{v})$ in the medium.

Funding: This research was funded by LPDP (Indonesia Endowment Fund for Education), grant number FR31122018165662.

Acknowledgments: The authors are grateful to iGEM ITB 2015 for the donation of mono-rhamnolipid production plasmid.

Conflicts of Interest: The authors declare no conflict of interest

\section{REFERENCES}

1. Tiso T, Zauter R, Tulke H, Leuchtle B, Li WJ, Behrens B, et al. Designer rhamnolipids by reduction of congener diversity: Production and characterization. Microb Cell Fact. 2017;16:1-14.

2. Abdel-mawgoud AM. Rhamnolipids: diversity of structures, microbial origins and roles. Appl Microbiol Biotechnol. 2010;86:1323-36.

3. Zhou J, Xue R, Liu S, Xu N, Xin F, Zhang W. High di-rhamnolipid production using Pseudomonas aeruginosa KT1115, separation of mono / di-rhamnolipids, and evaluation of their properties. Front Bioeng Biotechnol. 2019;7:1-9.

4. Sinumvayo JP, Ishimwe N. Agriculture and food applications of rhamnolipids and its production by Pseudomonas aeruginosa. J Chem Eng Process. Technol. 2015;6:2-9.

5. Amani H, Müller MM, Syldatk C, Hausmann R. Production of microbial rhamnolipid by Pseudomonas aeruginosa MM1011 for ex situ enhanced oil recovery. Appl Biochem Biotechnol. 2013;170:1080-93.

6. Du J, Zhang A, Hao J, Wang J. Biosynthesis of di-rhamnolipids and variations of congeners composition in genetically-engineered Escherichia coli. Biotechnol Lett. 2017;39:1041-8.

7. Cabrera-valladares N, Richardson A, Olvera C, Treviño LG, Déziel E, Lépine F, et al. Monorhamnolipids and 3-( 3hydroxyalkanoyloxy) alkanoic acids (HAAs) production using Escherichia coli as a heterologous host. Appl Microbiol Biotechnol. 2006;73:187-94.

8. Han L, Liu P, Peng Y, Lin J, Wang Q, Ma Y. Engineering the biosynthesis of novel rhamnolipids in Escherichia coli for enhanced oil recovery. J Appl Microbiol. 2014;117:139-50.

9. Studier FW. Stable cultures and auto-induction for inducible protein production in E. coli. Methods Mol Biol. 2014;1091:17-22.

10. Nur MMA, Hadiyanto $\mathrm{H}$. Enhancement of Chlorella vulgaris biomass cultivated in POME medium as biofuel feedstock under mixotrophic conditions. J Eng Technol Sci. 2015;47:487-97.

11. Fazli RR, Hertadi R. Production and characterization of rhamnolipids from bioconversion of palm oil mill effluent by the halophilic bacterium Pseudomonas stutzeri. Environ Prog Sustain Energy. 2018;38:1-6.

12. Wang Q, Fang X, Bai B, Liang X, Shuler PJ, lii WAG, et al. Engineering bacteria for production of rhamnolipid as an agent for enhanced oil recovery. Biotechnol Bioeng. 2007;98:842-53.

13. Cheng T, Liang J, He J, Hu X, Ge Z, Liu J. A novel rhamnolipid - producing Pseudomonas aeruginosa ZS1 isolate derived from petroleum sludge suitable for bioremediation. AMB Express. 2017:120.

14. Schneider CA, Rasband WS, Eliceiri KW. NIH Image to ImageJ: 25 years of image analysis. Nat Methods. 2012;9:671-5.

15. Zhao F, Liang X, Ban Y, Han S, Zhang J, Zhang Y, et al. Comparison of methods to quantify rhamnolipid and optimization of oil spreading method. Tenside Surfactants Deterg. 2016;53:243-8.

16. Rahim R, Ochsner UA, Olvera C, Graninger M, Messner P, Lam JS, et al. Cloning and functional characterization of the Pseudomonas aeruginosa rhIC gene that encodes rhamnosyltransferase 2, an enzyme responsible for dirhamnolipid biosynthesis. Mol Microbiol. 2001;40:708-18.

17. Lim H-K, Lee S, Chung S, Jung K, Seo J. Induction of the T7 promoter using lactose for production of recombinant plasminogen kringle 1-3 in Escherichia coli. J Microbiol Biotechnol. 2004;14:225-30.

18. Perfumo A, Rudden M, Smyth TJP, Marchant R, Stevenson PS, Parry NJ, et al. Rhamnolipids are conserved biosurfactants molecules : implications for their biotechnological potential. Appl Microbiol. 2013.

19. Nicolò MS, Cambria MG, Impallomeni G, Rizzo MG, Pellicorio C, Ballistreri A, et al. Carbon source effects on the mono / dirhamnolipid ratio produced by Pseudomonas aeruginosa L05, a new human respiratory isolate. $\mathrm{N}$ Biotechnol. 2017;39:36-41.

20. Rikalovic MG, Avramovic NS, Karadzic IM. Structure - Function relationships of rhamnolipid and exopolysacharide biosurfactants of Pseudomonas aeruginosa as therapeutic targets in cystic fibrosis lung infections. Prog. Underst. Cyst. Fibros.,2017;127-58. 
21. Li Z, Zhang Y, Lin J, Wang W, Li S. High-yield di-rhamnolipid production by Pseudomonas aeruginosa YM4 and its potential application in MEOR. Molecules. 2019;24:1433.

22. Bharali $\mathrm{P}$, Konwar BK. Production and physico-chemical characterization of a biosurfactant produced by Pseudomonas aeruginosa OBP1 Isolated from petroleum sludge. Appl Biochem Biotechnol 2011;164:1444-60.

23. Dhasayan A, Kiran GS, Selvin J. Production and characterisation of glycolipid biosurfactant by Halomonas sp . MB30 for potential application in enhanced oil recovery. Appl Biochem Biotechnol. 2014;174:2571-84.

24. Abdel-mawgoud AM, Hausmann R, Le F, De E, Markus MM. Rhamnolipids: detection, analysis, biosynthesis, genetic regulation, and bioengineering of production. Biosurfactants. 2011;13-56.

25. Wittgens A, Kovacic F, Müller MM, Gerlitzki M, Santiago-schübel B, Hofmann D, et al. Novel insights into biosynthesis and uptake of rhamnolipids and their precursors. Appl Microbiol Biotechnol 2017;101:2865-78.

26. Maqsood MI, Jamal A. Factors affecting the rhamnolipid biosurfactant production. Pak J Biotechnol. 2011;8:1-5.

27. Radzuan MN, Banat I, Winterburn J. Production and characterization of rhamnolipid using palm oil agricultural refinery waste. Bioresour Technol. 2017;225:99-105.

(C) 2021 by the authors. Submitted for possible open access publication under the terms and conditions of the Creative Commons Attribution (CC BY NC) license (https://creativecommons.org/licenses/by-nc/4.0/). 